\title{
Practice and exploration of the "student-centered" multielement fusion teaching mode in human anatomy
}

\author{
Xiumei Fu ${ }^{1,2} \cdot$ Xueyan $\mathrm{Wu}^{1} \cdot$ Donghui Liu ${ }^{1} \cdot$ Chengyun Zhang ${ }^{1} \cdot$ Honglin Xie $^{1} \cdot$ Ying Wang $^{3} \cdot$ Lijun Xiao $^{4}$
}

Received: 13 August 2021 / Accepted: 29 November 2021 / Published online: 7 January 2022

(c) The Author(s), under exclusive licence to Springer-Verlag France SAS, part of Springer Nature 2022

\begin{abstract}
Purpose Human anatomy is a core course of basic medicine and the first professional course for medical students. Traditional teaching includes "teacher-centered" instruction, passive learning, and a lack of interaction between teachers and students as well as between students. The aim of this study was to develop a "student-centered" multielement fusion teaching mode to address the mentioned drawbacks.

Methods A total of 141 clinical medical students from grades 2016 and 2017 of Chengde Medical University participated in this study. The students were randomly divided into four classes: two experimental classes and two control classes. The experimental classes experienced a "student-centered" multielement fusion teaching mode, while the control classes experienced a traditional teaching method. Formative assessments and questionnaires were used to assess the students' preferences and obtain feedback. Theoretical and experimental tests were carried out to detect the students' scores at the end of the semester. Results The results of the questionnaires demonstrated that $100 \%$ of the students agreed that the multielement teaching mode was better. In the experimental test, the students in the experimental group achieved a mean score of $16.50 \pm 0.3203$, which was significantly higher than that of the control group $12.65 \pm 0.4731(P<0.01)$. In the theoretical test, the average score of the experimental group was $45.86 \pm 0.6273$ and that of the control group was $46.59 \pm 0.6636$; thus, there was no significant difference between the two groups $(P>0.05)$.

Conclusion The application of a "student-centered" multielement fusion teaching mode obtained strong approval from the students. This teaching mode not only improved students' interest in learning and increased the interaction between teachers and students as well as between students but also enhanced students' competence and will lay a solid foundation for their future careers.
\end{abstract}

Keywords Student-centered $\cdot$ Multielement fusion teaching mode $\cdot$ Human anatomy $\cdot$ Teaching activities $\cdot$ Teaching methods

Xiumei Fu

fuxiumei2012@163.com

$\triangle$ Lijun Xiao

xiaolijun1233@163.com

1 Department of Anatomy, College of Basic Medical Sciences, Chengde Medical University, Chengde 067000, Hebei, China

2 Hebei Key Laboratory of Nerve Injury and Repair, Chengde 067000, Hebei, China

3 Department of Anatomy, College of Basic Medical Sciences, Mudanjiang College of Medicine, Mudanjiang 157011, China

4 College of Basic Medical Sciences, Chengde Medical University, Chengde 067000, Hebei, China

\section{Introduction}

Changes in medical education are on the agenda worldwide, and many medical schools have carried out reforms and experienced challenges $[9,14]$. Human anatomy, the science of the structures and functions of the human body and the relations of its various parts, is one of the cornerstone courses of medicine $[8,13]$. Moreover, human anatomy is one of the first basic medical courses medical students encounter and is a bridge between basic medical courses and clinical courses. Engels once said, "Without anatomy, there would be no medicine", which illustrates the importance of anatomy in medicine.

Studies have shown that anatomy is a necessary foundation for clinicians' development, and a thorough 
understanding of anatomy is a prerequisite for medical students to practice safely in a clinical setting [10, 16, 19]. Some clinical accidents are caused by poor knowledge of anatomy [6]. Surgery without solid anatomical knowledge can lead to increased mortality and morbidity [12]. These issues have forced medical schools to rethink the teaching and learning of anatomy. On the one hand, it is difficult for students to understand and apply human anatomy because of its complex content, abstract concepts, number of professional terms and lack of logical organization of systems descriptions. On the other hand, traditional anatomy teaching is mainly "teacher-centered" and based on lecturebased learning (LBL). This mode is systematic and complete, which is conducive to students building a complete knowledge framework. However, due to the lack of effective interaction between teachers and students as well as among students, students learn in a passive mode, and their learning enthusiasm is greatly affected. Moreover, students' mastery of the depth and breadth of knowledge is often limited by what is taught and what is not taught. At the same time, due to students' weak autonomous learning ability, the flexible application of knowledge is absent. Therefore, although students usually spend much time studying, the learning effect is still not ideal. The above factors have forced medical schools to introduce active learning activities and embrace the concept of "student-centered" education.

To this end, based on the establishment of a "safe" classroom climate, this study carried out a variety of learning activities, implemented a variety of teaching methods, and realized the transformation of classroom teaching in a gradual process from silence to question-and-answer exchanges, dialog, discussion, and debate. This approach allows every student to bring the spirit of "mastery" to the study of anatomy and to realize his or her own value. A "student-centered" multielement fusion teaching mode in human anatomy could also deepen students' internalization of learned knowledge, cultivate their professional spirit and practical operation ability, and expand the dimensions of their learning. Therefore, it was useful to practice the concept of "student-centered" learning, train future doctors in job competence and provide high-quality medical talent for society. These data provide practical demonstrations of teaching and learning reform in human anatomy instruction.

\section{Materials and methods}

\section{Course participants}

A total of 141 clinical medical students from grades 2016 and 2017 participated in this study. Sixty-two male and 79 female students were included, and their average age was $20 \pm 2$. The students were randomly divided into four classes: two experimental classes (class 14 from both grades) and two control classes (class 6 from both grades). The students had already completed the courses of basic chemistry, college English, medical higher mathematics, medical cell biology and so on, and in the second semester, they were going to learn human anatomy, histology and embryology, organic chemistry, medical physics and so on. Therefore, both classes in the same grade had the same major, similar basic knowledge and the same curriculum. Additionally, the human anatomy instruction in both classes was led by the same teacher, so the classes had homogeneity (Table 1). A "student-centered" multielement fusion teaching mode was used in the experimental group. First, LBL was taken as a guide to ensure the integrity and systematization of knowledge. Second, various teaching activities and teaching methods were carried out according to the contents, giving full play to students' subjective initiative and cultivating their comprehensive ability. Third, the combination of formative and summative assessments were used to test the learning effect. Generally, $1 \mathrm{~h}$ of LBL, $2 \mathrm{~h}$ of practical course, and $3 \mathrm{~h}$ of "student-centered" learning [such as jigsaw, peer instruction (PI), case-based learning $(\mathrm{CBL})$, problem-based learning (PBL) and the role substitution approach (RSA)] were arranged per week. The control group adopted the LBL, that is, the theory class was explained by the teacher, the practical class was also explained by the teacher first and then the students observed by themselves, $3 \mathrm{~h}$ of LBL and $3 \mathrm{~h}$ of practical class were arranged per week. All the participants completed the whole trial and provided informed oral consent regarding the data acquisition for this study.

Table 1 Participant characteristics

\begin{tabular}{ll}
\hline Contents & \\
\hline Male (number) & 62 \\
Female (number) & 79 \\
Age (year) & $20 \pm 2$ \\
$\begin{array}{l}\text { Stage of education (5-year medical } \\
\text { program) }\end{array}$ & Second semester of the first year \\
Courses already completed & Basic chemistry, College \\
& English, Medical higher \\
& mathematics, Medical cell \\
& biology, ect \\
Courses taken this semester & Human anatomy, histology and \\
& embryology, Organic chemis- \\
& try, Medical Physics, ect \\
\hline
\end{tabular}




\section{Methods}

\section{Building a "safe" classroom climate}

All the students were told the following in the first class: everyone should attend and finish the class on time. They were equal in class and they should treat others as they wanted to be treated. The students could ask questions at any time after first raising their hand. They should be honest and have the courage to admit mistakes. When communicating with others, they should be humble and courteous. The students should answer questions positively in class, and even if the answers were wrong, they should not be laughed at. Moreover, they should help each other and share what they learned.

\section{Developing various teaching activities}

\section{Integration of theoretical and practical courses}

The models and specimens were brought into the theoretical course. Meanwhile, the "Chinese Digital Human Anatomy System" (CDHAS) was integrated into the teaching process, so that students could observe the anatomical structure intuitively, vividly and three-dimensionally.

\section{Jigsaw}

Jigsaw teaching is a method of applying jigsaw ideas to teaching activities that is essentially a cooperative learning model based on contemporary cognitive science and constructivist theory. Jigsaw teaching was initially introduced in osteology and arthrology. The process is shown in Fig. 1. First, the students were divided into groups according to the learning tasks. Second, students in the same group were regrouped and given different tasks. Third, the students in charge of the same task formed an "expert group", and they reached a consensus after discussion. Fourth, the "expert group" returned to the original group to share the knowledge gained. Fifth, the original group reported to the class. Sixth, the teacher summarized the overall content and answered students' questions.

\section{Peer instruction}

The PI method refers to guiding every student to participate in the learning process, transforming traditional teaching into autonomous learning and cooperative inquiry based on analyzing a specific problem to construct an innovative teaching mode of independent and cooperative learning. The operational mode is shown in Fig. 2. The teacher handed out the pre-reading materials, gave a small lecture, and then threw out well-designed conceptual questions. The students were allowed to make independent choices first. A correct

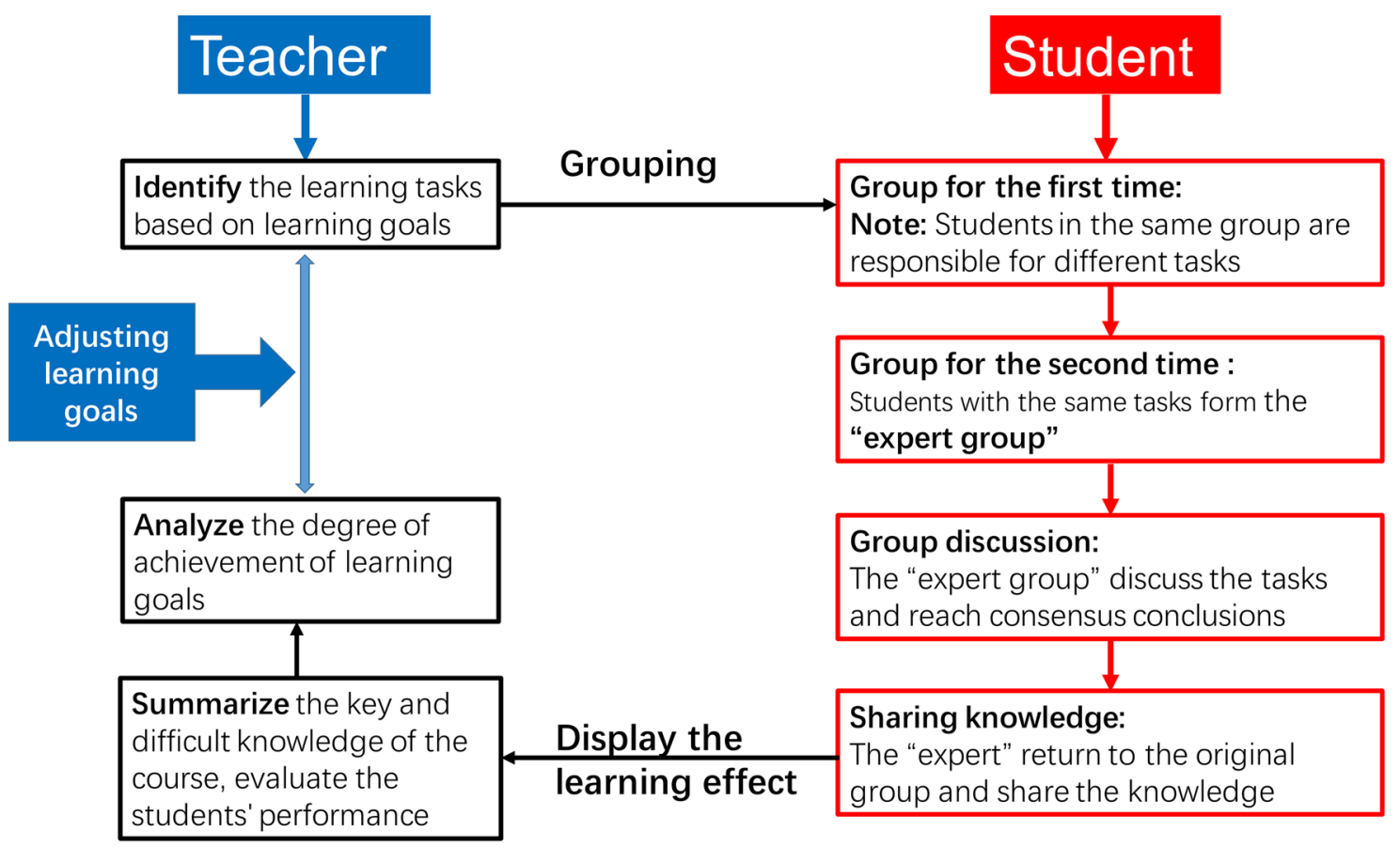

Fig. 1 Flowchart of the Jigsaw teaching activities in anatomy learning 


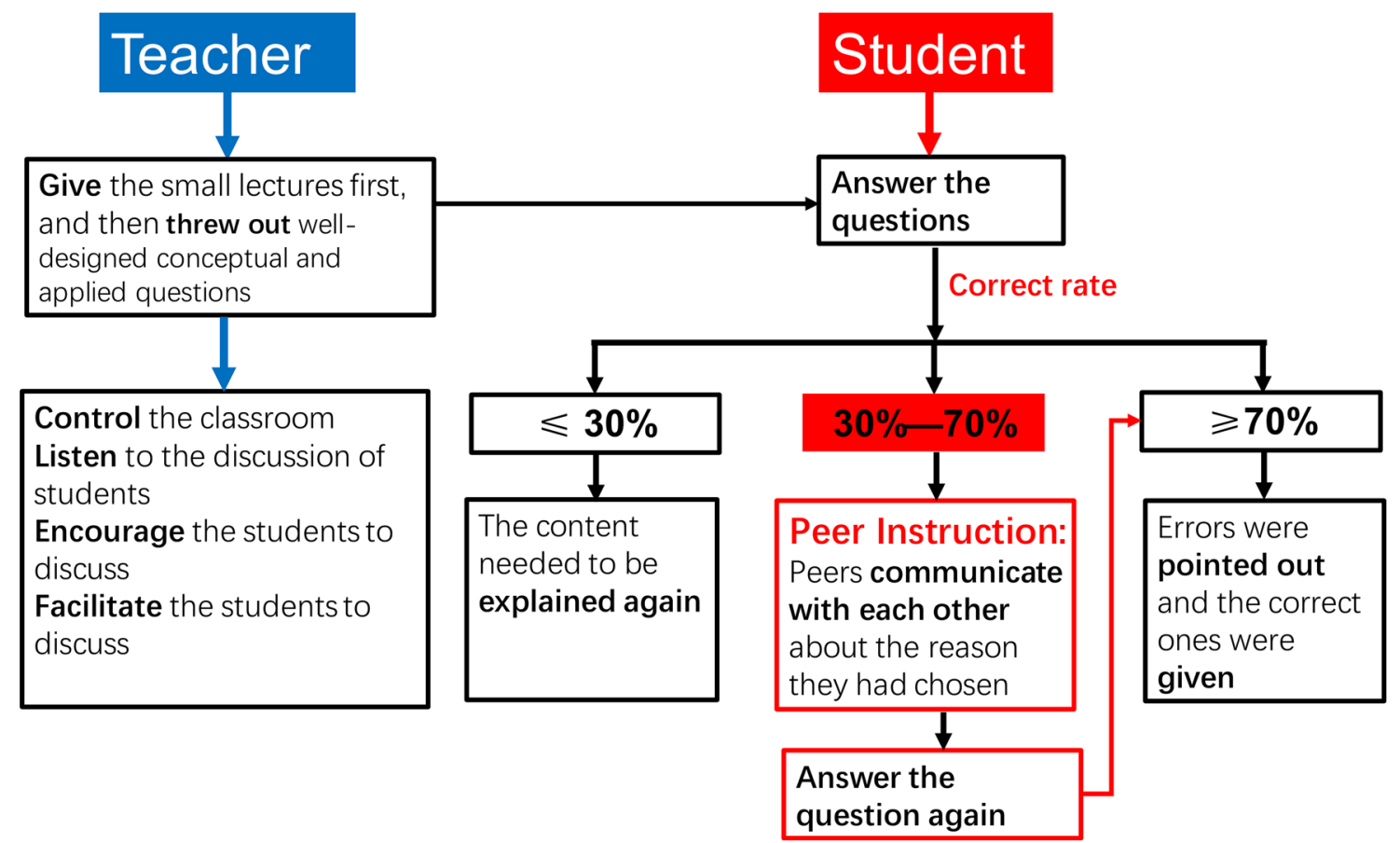

Fig. 2 Flowchart of peer instruction in anatomy learning

rate less than $30 \%$ indicated that the students were unclear about the concept, and the teacher needed to explain again. A correct rate of more than $70 \%$ suggested that most students had mastered the concept, and the teacher only needed to point out the mistakes and provide the answers. Interestingly, when the correct rate was between 30 and $70 \%$, the teacher should allow the students to communicate with their peers for a few minutes instead of explaining. Then, the second choice was made; surprisingly, the correct rate was often over $90 \%$, sometimes even reaching $100 \%$. At this time, the teacher listened to the students' explanation in each group and encouraged them to discuss.

\section{Implementing multiple teaching methods}

In the overall process of teaching and learning, we implemented CBL, PBL and RSA on the basis of LBL.

\section{Case-based learning}

CBL was used in the content closely related to clinical cases. The operational mode is as follows. First, the teacher sent out the case, and then the students searched the materials and discussed them in groups. Next, each group reported to the class. Finally, the teacher summarized the case and commented. For example, a uterine transplantation case was presented in a section on the female reproductive system. This case skillfully combined anatomical knowledge of the uterus with clinical knowledge of organ transplantation. In the case analysis, the students not only mastered anatomical knowledge of the position, shape, function and support of the uterus but also preliminarily discussed medical ethics and doctor-patient communication from the perspective of medical humanities. CBL can change boring anatomy teaching into specific case discussions, which arouse students' enthusiasm and initiative and improve the learning effect.

\section{Problem-based learning}

For the classic cases, we used PBL. The case of "Mr. Yu's back and leg pain" is given as an example. It began with $\mathrm{Mr}$. Yu's pain in his back and leg, followed by a medical history, observation of signs, clinical examination, the diagnosis and treatment. First, the students were divided into four groups, a chairman and a recorder were selected for each group. Driven by progress on the case, the knowledge was presented step by step. Usually, it took four classes for one case. The cases were handed out $3-5 \mathrm{~d}$ in advance. The students could use their spare time to collect information, find and analyze the problems, then try to solve them. They brought difficulties to class for intragroup and intergroup discussions. Throughout the process, the teacher did more about listening than explaining. More importantly, they should pull students back in time when they are too far away from the topic. Questionnaires were distributed to evaluate the effect of PBL to improve teaching and learning in the future. 


\section{Role substitution approach}

RSA is a teaching method that substitutes students for "teachers". This approach was applied mainly in practical courses. The specific implementation was as follows (Fig. 3). Take the practical course in "the connection of the upper limb bone" in class 14 from grade 2017 as an example. First, the students were divided into five groups (different colors represent different content, $n=7$ ). Each group was assigned different content (the sternoclavicular joint and acromioclavicular joint, shoulder joint, elbow joint; the connection between the radius and ulna; the radiocarpal joint along with the connections between the hand bones). Second, one "teacher" was selected from each group to explain their content. Third, two students from different groups were randomly paired to communicate with each other (i.e., each student was paired with another student from the other four groups). This pairing ensured that each student had mastered all five aspects of the content. Finally, to determine the learning effect for the students, the teacher performed a random check.

\section{Analysis and assessments}

\section{Formative assessments}

The formative assessments consist of mutual evaluations between teachers and students, mutual evaluations among students, assignments in and outside class and questionnaires. The questionnaires were designed according to the requirements of medical talent training and administered to the students in the experimental group. Then, the results were analyzed, and timely feedback was provided.

\section{Summative assessments}

At the end of the semester, theoretical and experimental tests were carried out. The test requirements and assessment standards were the same for both groups, and the scoring was performed together. The theoretical test was randomly selected from the test question bank. For the experimental test, 20 specimens from the same batch and of similar difficulty were prepared for the students to identify, and $1 \mathrm{~min}$ was allowed for each specimen. The total score was $60 \%$ theoretical score, $20 \%$ experimental score and $20 \%$ usual performance.

\section{Statistical analysis}

A statistical analysis of the test scores was performed using 19.0 SPSS. The measurement data are expressed as the mean \pm standard deviation $(\bar{x} \pm s)$. The two groups were compared with $t$ test analysis.

\section{Results}

\section{Results of the questionnaires}

As shown in Table 2, 100\% of the students highly approved this teaching mode. More than $90 \%$ of the students believed that the teaching mode stimulated students' interest, promoted learning, improved students' language skills, consolidated knowledge, contributed to the application of knowledge and prepared them for early clinical practice. More than $80 \%$ of the students agreed that the teaching mode could improve their ability to identify, analyze and solve problems; increase their breadth and depth of knowledge; strengthen
Fig. 3 Pattern diagram of the role substitution approach in anatomy learning
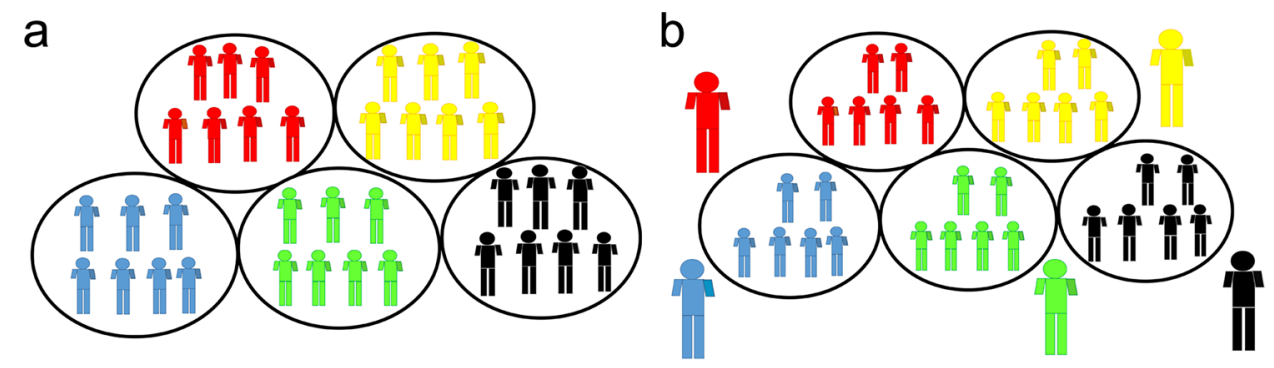

C

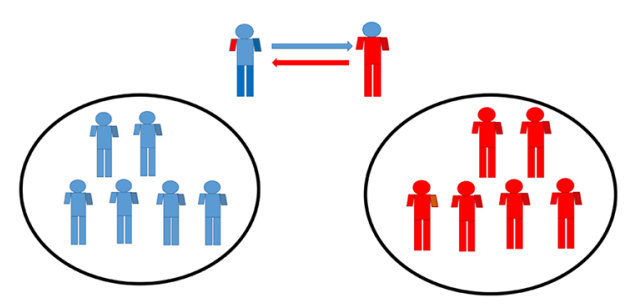

d

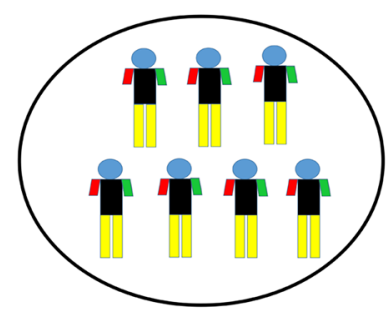


Table 2 Results of questionnaires in the experimental group

\begin{tabular}{|c|c|c|}
\hline Contents & Yes & No \\
\hline Can the teaching mode stimulate students' interest and promote learning? & $67(95.71 \%)$ & $3(4.29 \%)$ \\
\hline Can the teaching mode improve students' ability to identify, analyze and solve problems? & $56(80.00 \%)$ & $14(20.00 \%)$ \\
\hline Can the teaching mode strength students' ability to consult the literature? & $50(71.42 \%)$ & $20(28.58 \%)$ \\
\hline Can the teaching mode increase students' breadth and depth of knowledge? & $57(81.43 \%)$ & $13(18.57 \%)$ \\
\hline Can the teaching mode improve students' language skills? & $63(90.00 \%)$ & $7(10.00 \%)$ \\
\hline Can the teaching mode increase students' sense of teamwork and strengthen the relationship between students? & $58(82.86 \%)$ & $12(17.14 \%)$ \\
\hline Can the teaching mode consolidate students' knowledge and contribute to the application of knowledge? & $67(95.71 \%)$ & $3(4.29 \%)$ \\
\hline Can the teaching mode prepare students for their early clinical practice? & $65(92.86 \%)$ & $3(7.14 \%)$ \\
\hline Do you approve of the experimental teaching mode? & $70(100.00 \%)$ & $0(0.00 \%)$ \\
\hline
\end{tabular}

The teaching mode refers to the "student-centered" multielement fusion teaching mode

the teamwork and the relationship between students. Moreover, $71.42 \%$ of the students said that the teaching mode could strengthen their ability to consult the literature and prepare for future research.

\section{The theoretical and experimental test scores}

As shown in Fig. 4, the average score of the experimental test in the experimental group was $16.50 \pm 0.3203$, which was significantly higher than that in the control group, $12.65 \pm 0.4731(P<0.01)$. The average score of the theoretical test in the experimental group was $45.86 \pm 0.6273$, compared with the average score of $46.59 \pm 0.6636$ in the control group; there was no significant difference between the two groups $(P>0.05)$.

\section{Discussion}

Human anatomy is an important main medical course that is the basis of all medical disciplines. There are many problems with traditional teaching methods, such as a single teaching mode, less interaction between teachers and students and among students, and students' weak passive learning and autonomous learning ability [25, 28]. The concept of "student-centered" learning originates from the concept of "child-centered" learning by Dewey, an American child psychologist and educator, which centers students in the process and enables them to participate in learning happily and actively. Students are the main body of learning, and teachers should help them invest in the spirit of ownership and realize their own value in the process [5]. Therefore, the Department of Human Anatomy of Chengde Medical University reformed the teaching of human anatomy in 2013.

The classroom climate is the "soil" of classroom teaching and the "vital energy" of the existence, operation and development of subject teaching. Only in a "safe" classroom climate can students boldly express their views and truly participate. Therefore, the "safe" classroom climate is the guarantor of "student-centered" learning. Manzano-Sanchez D's study showed that a classroom climate could satisfy students' basic psychological needs and improve their learning motivation, prosocial behavior and classroom atmosphere [17]. Therefore, we first established a "safe" classroom climate at the beginning of the course. After several rounds of observation, we found that it was a very effective method.

Socrates, a medical educator, once said, "Education is not a matter of indoctrination; it is a lighting of fire". Classroom teaching should be the fire, as teachers ignite students' pursuit of truth. Therefore, our teachers carefully designed a
Fig. 4 Average scores of the experimental and theoretical courses. A The average scores of the experimental courses, $* P<0.01$, vs. the control group; B The average scores of the theoretical courses a

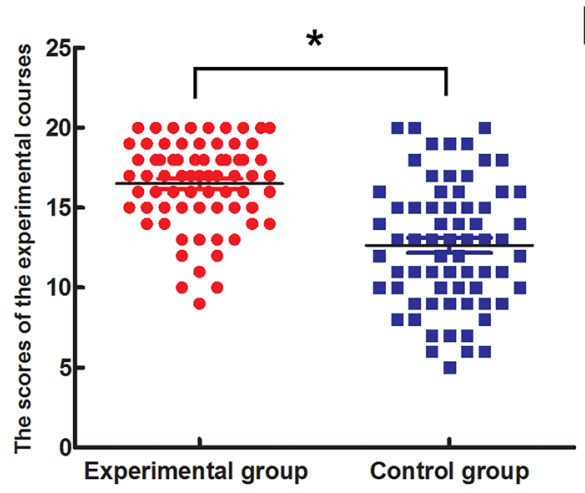

b

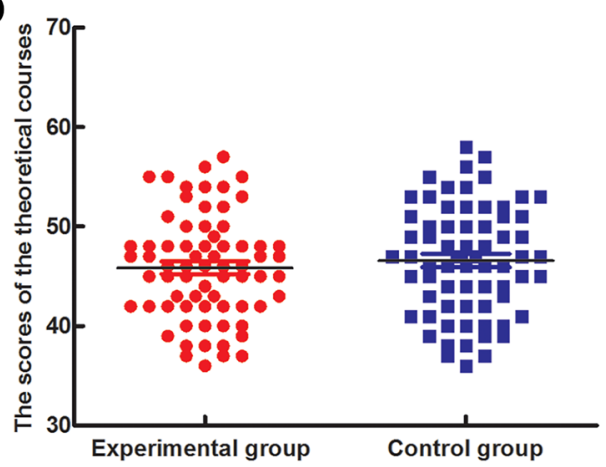


variety of learning activities to ignite the flame of students seeking knowledge.

First, practical and theoretical courses were integrated organically, and the CDHAS was added. The phenomenon of "disconnection" between the theoretical and practical courses was thus avoided. One study showed that the practical classes could not be well understood without face-toface classroom [20]. Justin F Shaffer et al. revealed that anatomical models were the most helpful materials for student learning [23]. Chytas et al. demonstrated that augmented reality is a highly acceptable and enjoyable anatomy teaching tool that showed remarkable efficacy in terms of helping students understand the three-dimensional organization of structures and achieve satisfactory examination results [7]. Therefore, anatomical models and/or specimens were added into theoretical classes. It not only avoids the boring of theory alone but also provides a visual impact for students, such "visible and tangible" objects were easy to understand and improved the learning. With the investment in teaching reform, the university introduced the CDHAS in 2014. To date, more than 600 students have used this system. CDHAS largely solved the problems of lack of cadaver specimens, unpleasant smell of soaked specimens and easy damage to the models. In the CDHAS, students can conduct structural separation and superposition and rotate an image $360^{\circ}$, so it brought a new experience [11].

Jigsaw is the literal translation of the "jigsaw puzzle", with a complete pattern being broken up into small pieces that can be reassembled by different people in a specific way. One of the important features of jigsaw teaching activities was the formation of the "expert group" by students who were allocated for the same question. Another feature is the "experts" returned to the original group sharing what they had gained. Through jigsaw teaching activities, students' language expression ability, problem analysis, problem solving, and team cooperation consciousness were improved. Thus, jigsaw teaching activities fully practice the "studentcentered" concept. One study suggested that jigsaw teaching activities promoted students' independent learning and provided opportunities for communication among group members [26]. According to the report of Oakes DJ, jigsaw teaching activities improved students' performance by engaging students in group work and peer-led learning [18]. Our questionnaire also confirmed this point.

In 1984, Professor Eric Mazur of Harvard University founded the PI in physics teaching practice. PI emphasizes initiatives and team cooperatives in learning, guides students to self-inquiry and stimulates their inner desire for knowledge [22, 27]. PI has been popular with teachers and students in many colleges and universities in China and abroad [1,3]. The research suggested that PI could improve learning efficiency [4]. An example of the locomotor system is "Where is the most common place for lumbar disc herniation?" The choices were as follows: anterior, posterior and posterolateral sides. The correct rate of the first time was approximately $50 \%$, and then they were asked to discuss with peers for $2 \mathrm{~min}$ and chose again. Surprisingly, the correct was $96 \%$ of the second time. Moreover, we were surprised to find that group discussion enabled learners to form a correct understanding soon. In fact, during the whole process, the important thing was how the students deduced the answer logically not the answer itself, which was the charm and the greatest gain of PI.

Tolstoy said, "Successful teaching need is not mandatory, but rather to stimulate interest". In addition to the active classroom activities mentioned above, we implemented a variety of teaching methods, mainly CBL, PBL and RSA. These methods increased the students' interest and participation.

CBL originated in the 1920s at Harvard Business School in the United States. It takes clinical cases as the entry point and presents knowledge gradually, so that students can learn the knowledge hidden from the cases [24]. Since human anatomy is opened in the first year of university, students have a strong desire for learning, but inadequate knowledge limits their access to medical information. Therefore, it is necessary to set up CBL courses to help students acquire clinical medical knowledge and establish clinical thinking. So the cases were carefully designed, in the locomotor system, cases with a history of obvious trauma and sensory and motor disorders were selected; in the visceral system, cases of common and frequently occurring diseases were selected; in the nervous system, typical cases related to key points such as the spinal cord and internal capsule were selected. Moreover, CBL pays attention to "student-centered" learning, mobilization of students' learning enthusiasm, and communication between teachers and students and among students.

PBL pedagogy is problem-based, student-centered and teacher-guided [29]. PBL maximizes students' autonomous learning, acquiring knowledge through a process of discussion, self-study, rediscussion and relearning [15]. Bains $M$ demonstrated that a combination of anatomy teaching and PBL could promote learning efficiency and students' comprehensive ability [2]. The Human Anatomy Department of Chengde Medical University began to implement PBL pedagogy in March 2013. So we accumulated some experience. In the experimental group, the following cases were applied: "Mr. Yu's back and leg pain", "Wandering abdominal pain", "Kidney stones", "What is wrong with my eyes?" and "Sudden hemiplegia". The instructional design hid the basic knowledge in the carefully designed case. At the end of each case, the students not only gradually mastered the anatomical knowledge but also understood the clinical knowledge. Moreover, humanistic literacy was involved in the whole case. In the whole process, students were the 
main body of learning, and their ability to express and solve problems could be well exercised. Teachers were the guides, information consultants and commentators. They guided the students to use various resources, collect relevant materials, discuss and analyze the problems, and determine the most suitable solutions.

RSA originated from role-play activities (RPAs) in the United States, but it differs from RPAs. It is a teaching method based on learning motivation theory, and humanist and constructivist learning theory. RSA was mainly carried out in practical courses of this study. On the one hand, practical classes consolidate and expand theoretical knowledge and provide a platform for students to display through interactions among themselves [21]. On the other hand, RSA puts forward higher requirements for students' learning by substituting students for teachers. Teaching is the sublimation and leap of knowledge. Only when knowledge is understood thoroughly can it be passed on to others. Therefore, when students played the role of "teacher", they would inevitably fully prepare what they had learned before explaining it to others. In summary, the introduction of RSA undoubtedly deepened the students' understanding and application of the knowledge and helped them achieve higher learning goals. Meanwhile, students' ability to provide information and respond to emergencies was enhanced. The real teachers provided supervision, confirmation, encouragement and guidance and prevented the emergence of the "forgotten corner" and "escaped fish" phenomena after assigning the tasks.

This study has some limitations. Due to the impact of COVID-19, some activities could not be well implemented online, resulting in a slightly small sample size for this study. In addition, the current evaluation system is not good enough to achieve a comprehensive evaluation; therefore, a long-term evaluation mechanism should be established for follow-up in the future. Moreover, as the "student-centered" multielement fusion teaching mode benefit the students in the experimental group, we made up for the control students through variety of teaching activities and methods on the next semester.

\section{Conclusion}

Medical teaching should focus not only on imparting basic theoretical knowledge to students but also on cultivating and developing students' abilities. In view of pain points in traditional teaching, this study carried out a variety of teaching activities, implemented a variety of teaching methods, and fully practiced the "student-centered" learning concept on the basis of establishing a "safe" classroom climate. This mode not only helps students learn basic medical knowledge but also develops their independent learning, communication, teamwork, problem finding, analysis and solving abilities and helps students establish critical thinking and clinical thinking abilities. We hope that the reform represented by the "student-centered" multielement fusion teaching mode implemented in this study can be popularized and applied in other majors or colleges to benefit more students.

Acknowledgements First, the authors sincerely thank those who donated their bodies to science so that anatomical research could be performed. The results from such research can potentially increase mankind's overall knowledge that can then improve patient care. Therefore, these donors and their families deserve our highest gratitude.

We thank Professor Jingfeng Xue for his valuable advice and guidance in the teaching reform and the teachers and students for their participation. Moreover, we thank the China Scholarship Council for its support for the overseas study program, which had enabled our deeper understanding of medical higher education and guides our way forward.

This work was supported by the Special Project on Personnel Training in the Western Region of the Administrative Committee of the China Scholarship Council ([2018]5028), the Research and Practice Project of Higher Education Teaching Reform in Education Department of Hebei Province (2019GJJG322); and the Educational Science Research Project of Chengde Medical University (20190002, 20190010); Key projects of the "14th Five-Year Plan" of Hebei Higher Education Society (GJXHZ2021-27).

Author contributions XF: project development, data analysis, manuscript writing. XW: data collection; teaching implementation. DL: data collection and analysis. CZ: teaching implementation, literature search. HX: teaching guidance. YW: manuscript editing, statistical expertise. $\mathrm{XL}$ : manuscript editing and project management.

\section{Declarations}

Conflict of interest The authors declare no conflicts of interest.

\section{References}

1. Albuquerque FDS, Assis TS, Oliveira Júnior FA, Freitas MR, Sá RCDSE, Martins VJB, Lins LSDS, Araújo JS, Sousa NAE, Gouveia RLB (2018) Effect of the use of a model with peer instruction for the teaching of membrane potential and action potential. Adv Physiol Educ 42:661-667

2. Bains M, Kaliski DZ (2020) An anatomy workshop for improving anatomy self-efficacy and competency when transitioning into a problem-based learning, Doctor of Physical Therapy program. Adv Physiol Educ 44:39-49

3. Bian H, Bian Y, Li J, Li Y, Ma Y, Shao X, Xu J (2018) Peer instruction in a physiology laboratory course in China. Adv Physiol Educ 42:449-453

4. Bloodgood RA (2012) Active learning: a small group histology laboratory exercise in a whole class setting utilizing virtual slides and peer education. Anat Sci Educ 5:367-373

5. Canoso JJ, Saavedra MÁ, Pascual-Ramos V, Sánchez-Valencia MA, Kalish RA (2020) Musculoskeletal anatomy by self-examination: a learner-centered method for students and practitioners of musculoskeletal medicine. Ann Anat 228:151457

6. Caswell FR, Venkatesh A, Denison AR (2015) Twelve tips for enhancing anatomy teaching and learning using radiology. Med Teach 37:1067-1071

7. Chytas D, Johnson EO, Piagkou M, Mazarakis A, Babis GC, Chronopoulos E, Nikolaou VS, Lazaridis N, Natsis K (2020) The 
role of augmented reality in anatomical education: an overview. Ann Anat 229:151463

8. Deng X, Zhou G, Xiao B, Zhao Z, He Y, Chen C (2018) Effectiveness evaluation of digital virtual simulation application in teaching of gross anatomy. Ann Anat 218:276-282

9. Emanuel EJ (2017) Reforming American medical education. Milbank Q 95:692-697

10. Estai M, Bunt S (2016) Best teaching practices in anatomy education: a critical review. Ann Anat 208:151-157

11. Fang B, Wu Y, Chu C, Li Y, Luo N, Liu K, Tan L, Zhang S (2017) Creation of a virtual anatomy system based on Chinese visible human data sets. Surg Radiol Anat 39:441-449

12. Kumar R, Singh R (2020) Model pedagogy of human anatomy in medical education. Surg Radiol Anat 42(3):355-365

13. Latif R, Mumtaz S, Mumtaz R, Hussain A (2018) A comparison of debate and role play in enhancing critical thinking and communication skills of medical students during problem based learning. Biochem Mol Biol Educ 46:336-342

14. Li H, Zhou X (2018) Medical education reform in China. Postgrad Med J 94:673-674

15. Liu Y, Xu Y, Li Y, Wu Q (2020) Application of problem-based learning and case-based learning integrated method in the teaching of maxillary sinus floor augmentation in implant dentistry. Peer J 16(8):e8353

16. Losco CD, Grant WD, Armson A, Meyer AJ, Walker BF (2017) Effective methods of teaching and learning in anatomy as a basic science: a BEME systematic review: BEME guide no. 44. Med Teach 39:234-243

17. Manzano-Sánchez D, Valero-Valenzuela A (2019) Implementation of a model-based programme to promote personal and social responsibility and its effects on motivation, prosocial behaviours, violence and classroom climate in primary and secondary education. Int J Environ Res Public Health 16:4259

18. Oakes DJ, Hegedus EM, Ollerenshaw SL, Drury H, Ritchie HE (2019) Using the jigsaw method to teach abdominal anatomy. Anat Sci Educ 12:272-283

19. O'Keeffe GW, Davy S, Barry DS (2019) Radiologist's views on anatomical knowledge amongst junior doctors and the teaching of anatomy in medical curricula. Ann Anat 223:70-76

20. Ortadeveci A, Ermez MN, Oz S, Ozden H (2021) A survey study on distance anatomy education: challenges unique to anatomy. Surg Radiol Anat 24:1-7
21. Pizzimenti MA, Pantazis N, Sandra A, Hoffmann DS, Lenoch S, Ferguson KJ (2016) Dissection and dissection-associated required experiences improve student performance in gross anatomy: Differences among quartiles. Anat Sci Educ 9:238-246

22. Rodis OMM, Locsin RC (2019) The implementation of the Japanese Dental English core curriculum: active learning based on peer-teaching and learning activities. BMC Med Educ 19:256

23. Shaffer JF (2016) Student performance in and perceptions of a high structure undergraduate human anatomy course. Anat Sci Educ 9:516-528

24. Singh K, Bharatha A, Sa B, Adams OP, Majumder MAA (2019) Teaching anatomy using an active and engaging learning strategy. BMC Med Educ 19:149

25. Triepels CPR, Smeets CFA, Notten KJB, Kruitwagen RFPM, Futterer JJ, Vergeldt TFM, Van Kuijk SMJ (2020) Does threedimensional anatomy improve student understanding? Clin Anat 33:25-33

26. Uppal V, Uppal N (2020) Flipped jigsaw activity as a small group peer-assisted teaching learning tool in Biochemistry Department among Indian Medical Graduate: an experimental study. Biochem Mol Biol Educ 48:337-343

27. Versteeg M, van Blankenstein FM, Putter H, Steendijk P (2019) Peer instruction improves comprehension and transfer of physiological concepts: a randomized comparison with self-explanation. Adv Health Sci Educ Theory Pract 24:151-165

28. Viswasom AA, Jobby A (2017) Effectiveness of video demonstration over conventional methods in teaching osteology in anatomy. J Clin Diagn Res 11:JC09-JC11

29. Zhang W, Li ZR, Li Z (2019) WeChat as a platform for problembased learning in a dental practical clerkship: feasibility study. J Med Internet Res 21:e12127

Publisher's Note Springer Nature remains neutral with regard to jurisdictional claims in published maps and institutional affiliations. 